\title{
Reply to 'A Second Opinion on "Operational Earthquake Forecasting: Some Thoughts on Why and How," by Thomas H. Jordan and Lucile M. Jones,' by Stuart Crampin
}

\section{Thomas H. Jordan ${ }^{1}$ and Lucile M. Jones ${ }^{2}$}

In folklore, a "silver bullet" is an effective weapon against werewolves and witches. In earthquake prediction, a silver bullet is a diagnostic precursor - a signal observed before an earthquake that indicates with high probability the location, time, and magnitude of the impending event (Jordan 2006). In his comment, Crampin (2010) claims that shear-wave splitting (SWS) observations provide a silver bullet. He asserts that seismology is thus capable of raising earthquake forecasting out of the lowprobability environment to which we assigned it in our recent opinion piece (Jordan and Jones 2010).

We find his arguments unconvincing. His conceptual basis is the notion that changes in shear-wave anisotropy are sensitive to changes in tectonic stress-a respectable hypothesis. But he burdens this concept with a thick pile of more dubious assumptions to somehow conclude that SWS observations can yield diagnostic precursors of large earthquakes. This is not the appropriate forum for a critical analysis of the prediction methodology he has advocated for several decades (e.g., Crampin et al. 1984). Suffice it to note that Crampin's (2010) elaborate train of geodynamic and seismologic reasoning carries his conclusions to a rather lofty station: "a single threeborehole SMS [stress-monitoring site] in central Italy... in principle could identify stress accumulation and stress-forecast all $\mathbf{M} \geq 5$ within Italy and smaller events nearer the SMS."

Very little data support his wildly optimistic assessment. His prospective testing appears to have captured only one successful prediction, an $\mathbf{M}=5$ earthquake in Iceland (Crampin et al. 1999), and even this claim of success has been disputed. Seher and Main (2004) performed a rigorous statistical analysis of Crampin et al.'s (1999) results and concluded that "it is not possible, based on the data, to formally reject the hypothesis that the magnitude 5 event was part of the normal background seismicity."

Nevertheless, Crampin (2010) is adamant about the consistency of the observations: "There are no exceptions: whenever appropriate shear-wave source-to-geophone recordings

1. Southern California Earthquake Center, University of Southern California, Los Angeles, California

2. U.S. Geological Survey, Pasadena, California exist, widespread stress accumulation has always been observed before large earthquakes." There are no exceptions is repeated three times. But at least one published study argues for an exception (Aster et al. 1990, 1991), and an earlier study by Ryall and Savage (1973) also presented some negative SWS results.

Crampin's (2010) representation of ideas as facts typifies an exclamatory style of argumentation that has all too often been employed by proponents of earthquake prediction schemes (see Geller 1997 for a critical review). A relevant critique was articulated by the International Commission on Earthquake Forecasting (ICEF) in its preliminary report (Jordan et al. 2009):

In many cases of purported precursory behavior, the reported observational data are contradictory and unsuitable for a rigorous statistical evaluation. One related problem is a bias towards publishing positive rather than negative results, so that the rate of false negatives (earthquake but no precursory signal) cannot be ascertained. A second is the frequent lack of baseline studies that establish noise levels in the observational time series. Because the signal behavior in the absence of earthquakes is often not characterized, the rate of false positives (signal but no earthquake) is unknown. Without constraints on these error rates, the diagnostic properties of the signal cannot be evaluated.

In the practical world of operational forecasting, what counts is not the subjective plausibility of a precursor hypothesis but its efficacy in delivering to users a reliable probability gain relative to the available long-term forecast. Given the propensity of individuals to believe in the rightness of their theories, an impartial third-party evaluation is necessary to confirm reliability and skill. The Collaboratory for the Study of Earthquake Predictability (CSEP) is setting up an infrastructure for this purpose (Zechar et al. 2009), and we encourage Crampin to develop SWS-based forecasting models suitable for CSEP testing.

As a final point, we would like to comment on Crampin's (2010) statement that "an underlying assumption of the ICEF 
report is that earthquakes cannot yet be deterministically predicted, so that only probabilistic earthquake (low-probability) forecasts are possible." Nowhere in the ICEF report is it assumed that earthquakes are intrinsically unpredictable. The report does conclude that no short-term prediction methodology has been qualified for use in operational earthquake forecasting:

The Commission has identified no method for the short-term prediction of large earthquakes that has been demonstrated to be both reliable and skillful. In particular, the search for precursors that are diagnostic of an impending earthquake has not yet produced a successful short-term prediction scheme.

However, the ICEF report explicitly endorses more research in this area:

Despite this negative assessment, the search for diagnostic precursors should not be abandoned, and more fundamental research on the underlying earthquake processes is required.

So the heroic quest for silver bullets should continue, including the investigation of SWS as a precursory stress-change indicator. Other, even more plausible hypotheses regarding earthquake predictability deserve to be carefully tested, such as whether diagnostic patterns of episodic tremor and slip can foretell megathrust earthquakes in subduction zones. But, given the manifest complexity of earthquake processes, we can hardly be sanguine that such research will extract us from a low-probability forecasting environment anytime soon. $\mathbf{k}$

\section{REFERENCES}

Aster, R. C., P. M. Shearer, and J. Berger (1990). Quantitative measurements of shear wave polarizations at the Anza Seismic Network, Southern California: Implications for shear wave splitting and earthquake prediction. Journal of Geophysical Research 95, 12,49912,473 .
Aster, R. C., P. M. Shearer, and J. Berger (1991). Reply. Journal of Geophysical Research 96, 6,415-6,419.

Crampin, S. (2011). A Second Opinion on "Operational Earthquake Forecasting: Some Thoughts on Why and How," by Thomas H. Jordan and Lucile M. Jones. Seismological Research Letters 82 (2), 227-230.

Crampin, S., R. Evans, and B. K. Atkinson (1984). Earthquake prediction: A new physical basis. Geophysical Journal International 76, 147-156.

Crampin, S., T. Volti, and R. Stefansson (1999). A successful stress-forecast earthquake. Geophysical Journal International 138, F1-F5.

Geller, R. J. (1997). Earthquake prediction: A critical review. Geophysical Journal International 131, 425-450.

Jordan, T. H. (2006). Earthquake predictability, brick by brick. Seismological Research Letters 77, 3-6.

Jordan, T. H., Y.-T. Chen, P. Gasparini, R. Madariaga, I. Main, W. Marzocchi, G.Papadopoulos, G.Sobolev, K. Yamaoka, and J.Zschau (2009). Operational Earthquake Forecasting: State of Knowledge and Guidelines for Implementation. Findings and Recommendations of the International Commission on Earthquake Forecasting for Civil Protection, released by the Dipartimento della Protezione Civile, Rome, Italy, 2 October 2009.

Jordan, T. H., and L. M. Jones (2010). Operational earthquake forecasting: Some thoughts on why and how. Seismological Research Letters $81(4), 571-574$.

Ryall, A., and W. U. Savage (1973). S-wave splitting: Key to earthquake prediction? Bulletin of the Seismological Society of America $\mathbf{6 4}$, $1,943-1,951$.

Seher, T., and I. G. Main (2004). A statistical evaluation of a "stress-forecast” earthquake. Geophysical Journal International 157, 187-193.

Zechar, J. D., D. Schorlemmer, M. Liukis, J. Yu, F. Euchner, P. J. Maechling, and T. H. Jordan (2009). The Collaboratory for the Study of Earthquake Predictability perspectives on computational earth science. Concurrency \& Computation: Practice and Experience 22, 1,836-1,847; doi:10.1002/cpe.1519.

Southern California Earthquake Center
University of Southern California
Los Angeles, California 90089-0742 U.S.A.
(T. H.J.)

Multi-Hazards Demonstration Project U.S. Geological Survey 525 S. Wilson Avenue Pasadena, California 91125 U.S.A. (L.M.J.) 